\title{
QSoSA (Quad-Space of Stage Acting) Model for Systematic Space Analysis of Stage Acting Based on Hermann Schmitz's Concept of Space
}

\author{
Hyo-Jung Moon'1), Sun-Young $\mathrm{Ihm}^{2}$ )
}

\begin{abstract}
In the field of performing arts, discussions about "performance space" have been conducted for a long time. Space is a key element of the performance intention, containing many objectives and creating meaning according to the theater's structure and stage purpose and the style of the work. However, the performer completes the meaning of the constructed space. In other words, the meaning of spatiality caused as a result varies depending on the performer's use of space or expression method. Therefore, for the essential discussion of the performance space, it is necessary to look not only at the theater or stage side but also from the perspective of the performer who leads the presentation. In addition, detailed perspectives, and criteria are needed to analyze the resulting multilateral spatiality with the flow and timing of the play. Therefore, this study proposes a QSoSA (Quad-Space of Stage Acting) model based on Hermann Schmitz's concept of space.
\end{abstract}

Keywords: QSoSA Model, Stage Acting Space, Performance Space Convergence Model, Hermann Schmitz, Emotion Space

\section{Introduction}

\subsection{Background}

Performing arts encompasses all kinds of art in a stage space such as plays, operas, musicals, Madang plays (a traditional Korean theatrical art form), and other eventful performances. Furthermore, with the introduction of computer technology and four-dimensional special effects, such as holograms, performing arts is expanding to be a multidimensional fusion genre.

In performing arts, necessary devices and facilities can be installed in a "performance space,"

Received(September 06, 2019), Review Result(1st: September 23, 2019, 2nd: October 29, 2019), Accepted(December 23, 2019) 1) (Student) 03063 Interdisciplinary Program in Studies of Art, Graduate School, SungKyunKwan University, Seoul, Korea email: m_jiwon@naver.com

2) (Research Professor, Corresponding Author) 04620 Development of Smart Community Policing System Research Center, Dongguk University, Seoul, Korea

email: sunnyihm@dgu.ac.kr 
QSoSA (Quad-Space of Stage Acting) Model for Systematic Space Analysis of Stage Acting Based on Hermann Schmitz's Concept of Space

a place wherein the stage and audience can be in a close association while presenting a performance; in addition, "theater," a modern concept, is synonyms to performance space. However, "performance space" is not limited to the features of a theater, which is mainly categorized into stages and auditoriums.

Moreover, performing arts has a process characteristic in which the performers and audience experience time and space together, alongside sharing the meaning and emotion of the performance. Thus, it includes all spaces wherein the performers and the audience experience and create together during the performance.

However, even if the performers and the audience are together in the same performance space, each shares a different space altogether. First, the performers and the audience have an interactive view of each other, and the space to be experienced varies in accordance with their positions. The space one experiences will vary depending on where one is positioned on the stage or what movements or lines one has when the number of performers is more than one. In addition, the audience share and experience spatiality differently, depending on whether they are physically near or far from the stage. Second, the meaning of "space" depends on the performer's emotion; the space may be filled dramatically, depending on the performer's emotional immersion and expression, and the performance quality of the performer may vary depending on the extent to which the audience shares the performer's emotions.

Therefore, with respect to performance space, it is necessary to systematically discuss the multivariate spatiality, resulting due to the performer's use of space or expression from more diverse perspectives; this aspect thereby requires detailed viewpoints and criteria for a systematic discussion and analysis of the performance space.

Hence, this paper proposes a reference concept as a visualized model that can be more concretely analyzed through Hermann Schmitz's spatial theory; in addition, it explores the convergence of the space created by the performer and the audience as they experience and share it in due course of time and discusses the five-dimensional spatiality newly established through the convergence of space. Furthermore, this discussion is expected to have a developmental meaning as a fundamental study on the research of performances in which various computer technologies are combined and fused in multidimensional ways.

In this paper, we first derived the elements and characteristics of spatial division through an examination of the elementary concept of "stage acting"; these factors were further examined by integrating Hermann Schmitz's concept of "spatial theory." Additionally, on the basis of the analysis results, Quad-Space of Stage Acting (QSoSA) is proposed, and the concept and standard that can specifically classify the spatiality of stage acting are presented. Further, the 
concept of "stage acting" is discussed in Section 2.

\subsection{Related Study}

The space study on performance is categorized into two, namely, stage space and actor space. Spatial research on the stage mainly consists of place and structural characteristics, such as theater structure, stage design, and stage composition. Spatial research on actors deals with space based on physical perception and movement or experience-based space. Moreover, related studies on the body and the space of movement were mainly preceded in the fields of acting and dance.

Kim Hye-ran[1] conducted a visualization of body movements by applying spatial shapes and expressive elements, and Kang Joo-sun[2] developed an emotional model of K-pop dance based on Rudolph Laban's theory of motion. In addition, studies on emotions and space were actively discussed in various academic societies, ranging from the fields of architecture to arts and computer science. Ham Jun-seok et al.[3] conducted a study visualizing the characters' emotions in Hamlet by employing a psychology-based artificial emotion model. Song[4] conducted a study based on James Rüssel's emotional archetype model and K. Hevner's musical emotional model, and this study on the relationship between color and emotion of healing video art presented a prototype model and attempted to combine it with video art.

In addition, the domestic research centered on Hermann Schmitz's theory, which was proposed as the basis theory in five studies, and all five studies were by the same author, Ha Sun-gyu[5].

\subsection{Limitations of the Research}

AAs previously mentioned, performances cover a wide and comprehensive genre, and there are various places where performances are presented. Therefore, this study discusses genres, such as plays and musicals, in which fictional "drama" is performed by actors. In addition, the performance venue is limited to the "theater," as it is the modern concept that separates the stage from the audience with an elemental focus on the "actor" leading the play. Therefore, in this paper, the term "stage acting" is used to more specifically express the media, genre, and elemental restrictions, such as performances and stages, and actors and acts.

Moreover, as discussed in previous research, there prevail a few domestic studies on Hermann Schmitz. Thus, the concepts and terminology of Schmitz's spatial theory dealt in this 
QSoSA (Quad-Space of Stage Acting) Model for Systematic Space Analysis of Stage Acting Based on Hermann Schmitz's Concept of Space

study are based on the research contents of Ha Sun-gyu. Therefore, terms such as "extended space," "directional space," "place space," and "emotional space" - as defined by Ha Sun-gyucan be redefined later by other researchers in the future.

\section{The Concept and Spatiality of Stage Acting}

\subsection{Definition of the Concept of Stage Acting Terminology}

A dictionary meaning of "acting" is that an actor expresses a character or action in a drama. Therefore, the term "stage acting" used in this study can be defined as a concept that means "a story of fiction by an actor appears in a performance art genre such as a play or musical" in a stage space, i.e., "an act of performing or expressing a character in the play."

\subsection{Characteristics and Spatiality of Stage Performance}

\subsubsection{Characteristics of Stage Acting}

As a genre, the performing arts includes a wide variety and range of types. Among them, a typical genre of performance, in which an actor leads a production onstage, is "play" (theater). In modern times, however, the genre of the play is also changing and developing into various formats, including musical plays, nonverbal performances, and audience participation. Furthermore, its forms are demarcated, making it increasingly meaningless to distinguish between genres and forms.

The four main elements of a play are the stage, actor, audience, and drama. The play shares the enactment's message and emotion with the audience via the actor's performance through the stage space, and the meaning is completed through the process of reinterpretation. The audience shares the play through the actor's performance in the audience, and the meaning is completed through the process of reinterpretation. In other words, performance indicates that each component-stage, actor, audience, and play-completes the meaning with close interrelationship during the presentation[6].

Stage acting has many differences from movie acting, such as movies and TV dramas. The difference between theatrical and cinematic art is intrinsic to playwright Henri Guier. "Movies do not have the presence that exists only in theater," said Henri Guey, presenting nine criteria -including space, time, audience, and acting-for the media differences between plays and movies. It also presented characteristics that actors and audience share the same time and 
space, and there are differences in plays and movies, such as the process of an actor's continuous and completed performance[7]. In other words, stage acting has a presentness, continuity, and one-time-ness that share the time and space of a performance with the audience in a limited theater space unlike a movie or TV drama. This intrinsic characteristic does not change even if a technical device, such as $4 \mathrm{D}$ or computer graphics, is introduced on the stage or an actor is replaced with a virtual character, such as a hologram.

\subsubsection{Spatiality of Stage Acting}

Space is a core element of the performance intention, and it contains and creates a lot of meanings and intentions according to the purpose of composition, form, and style used. In addition, it is intended to allow the audience to appreciate the play aesthetically and imply the essential purpose of sharing the performance experience with the actor, and the audience through mutual processes. Therefore, the performance space is said to be a comprehensive concept that includes all elements of a performance[8].

In this paper, we also fully agree that the performance space should be viewed as a broad category with a comprehensive meaning that includes many elements. However, to further clarify the discussion on performance space, it is necessary to share not only the constructive aspects of the performance venue but also the experiences of the actors and audience leading the performance, as well as the spatial characteristics caused by the process of sharing the time, space, and emotions. This is because the space in which the actor and audience realistically exist in the category of performance is quite different, and the space experienced by the actor and the audience differs according to the interactive view of each other.

The theater where the performance takes place is largely divided into stage and audience seating. In general, the stage area is divided into "where the actors perform" and "where the audience views the performance." A stage is an architectural equipment space in which the background or technical equipment necessary for a performance exists.

American architect Frederick John Kiesler told the audience who watched the proscenium stage that the stage is nothing more than a relief, and the traditional stage may be a space for actors, but not for the audience[4]. However, as the performance begins and actors appear, the stage space becomes meaningful as a fictional space existing within the play. Furthermore, it has an ironic characteristic that exists as a space of virtual images, which is not actually present, and a dramatic space presented by the script or director[9]. That is, as presented in Figure 1, the stage has a device characteristic that is a medium between reality and drama. 
QSoSA (Quad-Space of Stage Acting) Model for Systematic Space Analysis of Stage Acting Based on Hermann Schmitz's Concept of Space

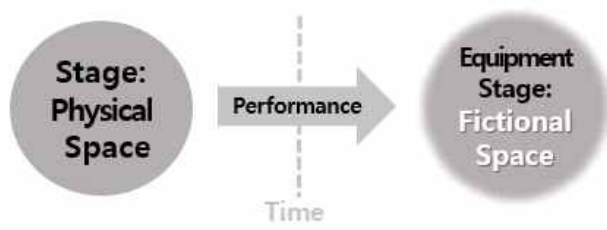

[Fig. 1] Change of Stage Characteristics after the Start of the Performance

\subsubsection{Spatiality of Acting}

The actor goes through numerous spaces a day until he gets on stage. In addition, the actor must cross the stage, and preparatory space during the performance, co-existing as the play's essential "I" and character. Specifically, the actor must continuously express the emotions of the play's characters on the boundary line between the stage space and the real space, delivering the imaginary space that the work implies to the audience. Therefore, the actor's acting space is not just a stage.

In his book, Terry Hodson speaks of the actor's space, emphasizing the actor's use of space and the creation of space beyond the stage: the illusion of space as an important research subject.

"How to use and organize theater spaces, and how to create [an] "illusion" of space beyond the visible stage[,] are important research tasks. Actors should also decide what kind of space to create in the first base of the play, as to the way they use the space they work."[10]

As Hodson says, acting spaces may have different meanings from the intention of directing, depending on how the actor uses, and expresses the space through the body. For this reason, the actor must seriously consider how creative space will be formed in the intended stage space.

Unlike movies and TV dramas, performances have many limitations in expressing the background and location of the play. Thus, the play's background, which cannot be expressed on stage, is sometimes given a device meaning by lighting or symbolically through the actor's performance. Through the actor, the stage becomes a desert and space. In addition, watching an actor's movement of running in place onstage, the audience can feel the spatiality of the field that can run endlessly. Therefore, actors must express the play's meaning through their emotions and movements within the limited space of the stage and create a new space for the play. In other words, stage acting forces actors to expand; they must create not only the fictional space of the play but also the "illusion" space of the play beyond the stage through the way they use and express space.

In addition, the purpose of the performance is to convey the meaning and emotions of the 
play to the audience through the actor's performance and increase the empathy and satisfaction the audience appears to equate with the character's emotion in the play. Thus, it is also the essential purpose of acting that an actor must "play" the audience's emotions imbued with the play's flow, constantly occupying the audience's space while overwhelming the theatrical atmosphere. Therefore, the degree, to which an actor occupies space through acting closely relates to the quality of acting. As presented in Figure 2, if an actor takes emotional possession of the audience's space while conducting a perfect performance, the audience will identify with the person in the play, and their level of empathy will increase.

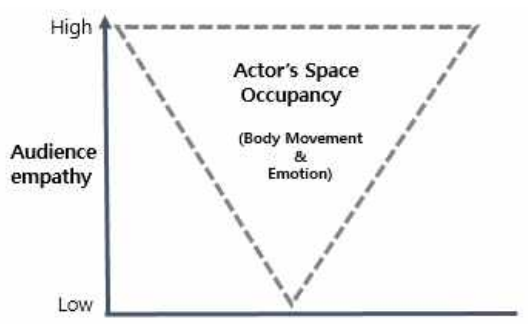

[Fig. 2] Proportionality Level of the Actor's Space Occupancy and Audience Empathy

Namely, the actor's acting space includes not only the stage space but also the audience space; when the stage and audience spaces are emotionally occupied, it is only when the performance is qualitatively perfected. This means, for an actor, emotions are the original and motive of acting, simultaneously leading to concrete actions for expressing the goal of the play. Therefore, the body, emotion, and space in studying an actor's performance are not subject to separate analysis but are factors that lie in close continuity. Specifically, the study of acting is a major question of philosophy and of science; it should include such notions as self-concepts as to who we are and how we act, know, and feel in response to the environment, perceptions, cognitive processes, memories, and emotions[11].

As mentioned in Chapter 2, the space of stage acting has the following characteristics. First, the stage space consists of an architectural structure with its mechanical characteristics since the beginning of the performance, existing as a "false place" within the play. Thus, the stage space has "device emptiness." Second, the acting space has a) "creativity," which produces a new imaginary space beyond the limits of stage space, and b) "occupancy," which emotionally occupies the stage and audience spaces. Third, both the stage and acting spaces have a "sharedness" with the audience. These three characteristics are presented in Figure 3. 
QSoSA (Quad-Space of Stage Acting) Model for Systematic Space Analysis of Stage Acting Based on Hermann Schmitz's Concept of Space

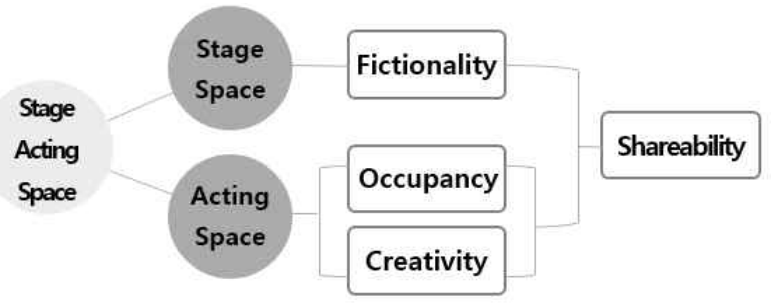

[Fig. 3] Spatial Characteristics of Stage Acting

\section{Hermann Schmitz's <Choriologie>}

\subsection{Hermann Schmitz's Philosophy Background and Aesthetics Theory}

Hermann Schmitz, a German phenomenologist, is credited with having made the most outstanding achievement on the body (sex) of the 20th century, along with Merleau-Ponty. The concept of a phenomenological space reveals the relationship between human beings and space in a position to look at the space around the human body and recognize the nature of space arising from all human experiences.

Hermann Schmitz pays close attention to the "experience of body feeling." This "experience area" is an aspect of all the sensory and emotional experience areas, where humans sense, understand, and evaluate the unique feelings of the body in specific life situations, that is, the unique feelings that the body senses. Attention is drawn to the unique and vivid ecology. In other words, it encompasses the particular world surrounding human beings and the generality of them - the state of experience that accepts individual moods and situations

\subsection{Hermann Schmitz's Characteristic of <Choriologie>}

Hermann Schmitz phenomenologically subdivided the dimensions of spatiality as 1) "extended space (Weiteraum)," 2) "directional space (Richtungsraum)," 3) "emotional space (Gefühlsraum)," and 4) "place space (Ortsraum)," which is familiar to us[12].

First, "extended space" means the lowest and most basic layer of space experience. That is, the state of experience that does not even recognize the atmosphere or fundamental spatiality that surrounds it without any fixed directional orbit or sense of space. Second, "directional space" is an experience, in which all orientations-left, right, right and right, up, down-are oriented by the basic human perception and physical motion, so physical orientation space is 
the domain of kinematics. Additionally, the third "place space" means a space that we often think of as a three-dimensional location[13].

Ha Sun-gyu mentioned the layers and characteristics of Hermann Schmitz's "extended space" and "directional space":

"These are not features or parts of three-dimensional space, but different dimensions of spatiality that humans feel specifically through their bodies. According to Schmitz, there is a kind of 'genetic and structural order' between these layers. 'Extended space' is the most basic and lower level of space experience, and 'directional space' emerges on the layer of space. Subsequently, based on the layer of directional space, the so-called 'three-dimensional space', that is, 'objective-physical place space,' is written and placed."[14]

The "emotional space" is the most interesting layer of Hermann Schmitz's spatial theory. The main reason why the researcher suggested Schmitz's theory of space as the basis for discussing the spatiality of stage acting is "emotional space." Schmitz suggests that "emotions are widespread in space" and that when it comes to feelings, the unique atmosphere or Stimmung (mood) power perceived in a "place" or a certain situation is the "occupied" subject. It also argues that emotions are not subjective and internal, but rather are spatial surroundings of the subjective from the outside.

Thus, the emotional space experience is always accompanied by the state of the subjective directly involved, emotional feelings contained within it, or emotional surprises that the body feels, thus the close affinity with the expansion space or direction space. Nevertheless, the emotional space should be seen as a layer of unique experience. The level of emotional space claimed by Schmitz is presented in Figure 4.

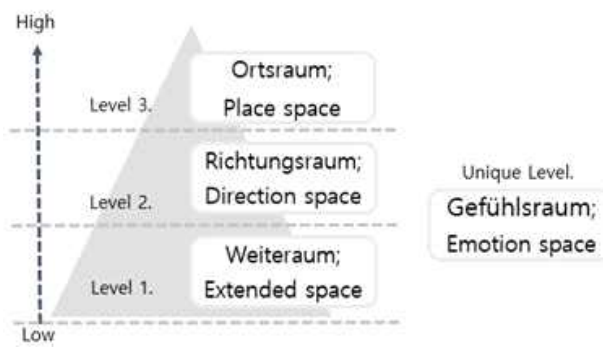

[Fig. 4] Spatial Level of Hermann Schmitz with the Emotional Space

The discussion of human emotions is actively debated in various fields-such as engineering and emotional science, as well as psychology and art-and the scope of research is expanding. Therefore, Schmitz's concept of the spatialization of emotions suggests new implications and 
QSOSA (Quad-Space of Stage Acting) Model for Systematic Space Analysis of Stage Acting Based on Hermann Schmitz's Concept of Space

research points in the study of stage acting, which acts emotions through the physical experience within the limited space of the stage. In addition, it has meaning as a grounded theory for analyzing the characteristics of spatiality that change according to the performance process.

Based on the spatial characteristics of stage acting stemming from Chapter 2 and Hermann Schmitz's spatial concept, the following meanings are derived.

First, the stage space exists as a device for a play, namely, a fictional place space. Although the stage space is fictitious, it has the conceptual characteristics of Schmitz's "place space," because it is constructed architecturally and meaningfully according to the intention and purpose of the production and physically that exists on the stage.

Second, acting space is a physical space that the actor experiences through physical movement, a space of imagination, and has the characteristic of occupying space emotionally. Thus, acting space has the conceptual characteristics of Schmitz's "directional space," "extended space," and "emotional space."

Third, the stage acting space is shared with the audience by identifying the characters' emotions and sharing the meaning and emotions of the drama. Therefore, the stage acting space has a conceptual characteristic of Schmitz's "emotional space." These three characteristics are presented in Figure 5.

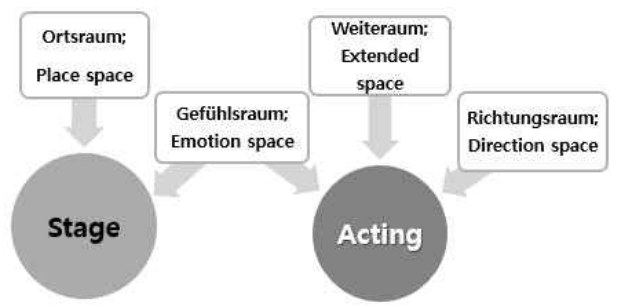

[Fig. 5] Interrelationship of Hermann Schmitz's Spatiality and Stage Acting Space

\section{QSoSA: A Study on Four Spatial Proposals and Stages of Convergence}

\subsection{Proposing "QSoSA": Quad-Space of Stage Acting}

This chapter is based on the spatial characteristics of stage acting derived from Chapter 2 and the concept of space in Chapter 3, "Hermann Schmitz." Furthermore, based on this, we propose a "QSoSA (Quad-Space of Stage Acting)" model for spatial analysis of new stage acting. 
The "QSoSA" model is a methodology that can further analyze the comprehensive concept of the performance space. Therefore, using this methodology, we analyze the convergence of the process of performance, specifically the space that changes and is created over time. The results of the analysis have the purpose of obtaining a qualitative completeness of the performance.

In this paper, we present the standard concept by dividing the stage acting space into four spatial elements through the "QSoSA" model. Then, we will visualize and show the interrelationship between the four spatial elements specified.

\section{2 "QSoSA" Components and Concepts}

The four space elements in the QSoSA model are "equipment space," "occupied space," "creative space," and "shared space." The concept of each element is as follows.

First, "equipment space" refers to a space that is constructed and constructed mechanically. This embodies a fictional place for an onstage play.

Second, "occupied space" is the space occupied when the actor moves. The actor physically moves onstage. The space occupied is referred to in this case. It is a space where the actor is emotionally immersed in the play, grasping and occupying its atmosphere and energy.

Third, "creative space" refers to the "illusion space" that actors create through their performance and beyond the limitation of stage space. This is the case, for example, in deserts and spacecraft, as mentioned earlier in Chapters 2 and 3. The actor will use the performance to produce the illusion of being the target place in the play, beyond the limits of the first space-the physical "equipment space." In other words, "creative space" refers to this extended fantasy space.

Fourth, "shared space" means that if an actor communicates the play's meaning to the audience through acting, over time, the actor, and audience will unite with the same emotion. This emotional space is called "shared space."

\subsection{Structure of New Model}

This paper aims to suggest a QSoSA model. Here a model refers to a pattern, plan, and description for showing an object, system, conceptual structure, and function. In essence, a model consists, first, of presenting a structure for explaining certain facts and functions for moving the arrangement of the structure[15]. Therefore, in this paper, the structure, and function are first explained. Then, the constraints are clarified for the proposal of the "QSoSA" 
QSoSA (Quad-Space of Stage Acting) Model for Systematic Space Analysis of Stage Acting Based on Hermann Schmitz's Concept of Space

model, which consists of four elements, as defined in Section 4-2. The elements are represented in the form of circles. The structural form of the QSoSA model is presented in Figure 6.

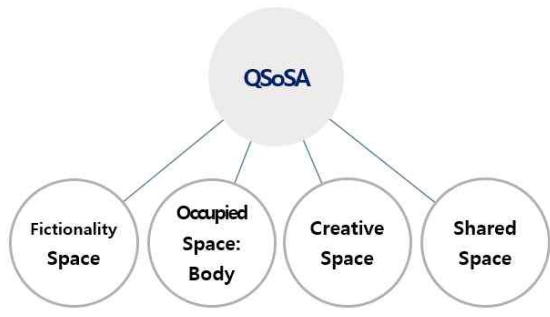

[Fig. 6] Structural Organization of Proposing New QSoSA Model

\subsection{Functions of QSoSA Model}

QSoSA has five functional characteristics:

(1) The four elements are indicated by solid or dashed lines, depending on the nature.

Of the four elements - physical elements - that can be clearly measured in length, width, etc., are indicated by solid lines. In contrast, elements whose physical size and extent cannot be measured-i.e., chemical elements-are indicated by dotted lines. Each element may be separated from each other and, conversely, combined. However, when two or more elements are combined, the intersecting portion is indicated by a dotted line. However, when the physical elements are joined-that is, when the solid and dotted lines are joined-all of the intersecting portions are indicated by solid lines. Figure 7 presents the properties of each element's line shape when combined.

(2) Four elements have physical and chemical properties for each element.

First, "equipment space,"-the first space of the model structure-has physical properties because it is constructed on stage for the purpose of the play. On the other hand, "creative space" and "shared space," which are the third and fourth spaces of the model structure, have chemical properties because they are based on the emotions of the actors and audience, respectively.

Furthermore, the second part of the model structure, "occupied space," is a space that has both physical and chemical properties. The occupied space is further divided into two sub-elements, depending on the physical, and chemical properties. The first is the "Physically Occupied Space (Body)," which is calculated according to the degree of movement of the actor's body. Second is "Emotionally Occupied Space (Emotion)," which is according to the actor's emotional commitment and control. Therefore, "equipment space" with physical 
characteristics in stage acting is indicated by a solid line, whereas "creative space" and "shared space" with invisible chemical properties are indicated by dotted lines. Based on this, "occupied space," which has both physical and chemical characteristics, can be expressed in two ways. The two detailed elements of "occupied space" are indicated by the solid line of "Physically Occupied Space," and "Emotionally Occupied Space" is denoted by a dotted line.

(3) The four elements are represented in different colors.

To clarify the structural relationship of the proposed model, we used different colors to express the meanings of the elements. Color relates to the four elements of the play. The colors are as follows: "Equipment space" is indicated by green, "occupied space" by red, "creative space" by yellow, and "shared space" by orange. Henceforth, these colors will be referred to as the following: $\mathrm{G}$ (green), $\mathrm{R}$ (red), $\mathrm{Y}$ (yellow), and $\mathrm{O}$ (orange).

The four elements of the play introduced in Section 2-2 and the intrinsic colors are semantically related. The equipment space relates to the stage, and the occupied space relates to the actor, specifically the main actor of the stage presentation. Furthermore, since creative space can be called the space of drama completed through the actor's acting, it has a relationship with "play" or drama. "Shared space" refers to the communication between the actors and audience and relates to both the actors and audience. Figure 8 illustrates this relationship. However, the spatial elements of QSoSA have a semantic relationship with the play's four elements, which do not match QSoSA's elements

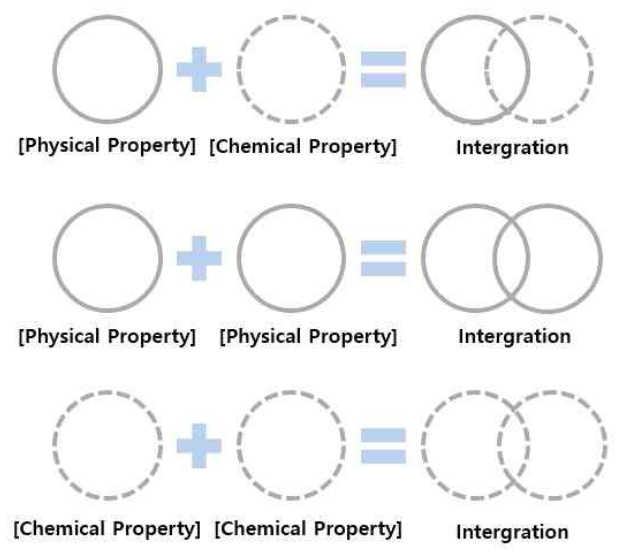

[Fig. 7] Line Shapes by Elements of "QSoSA"

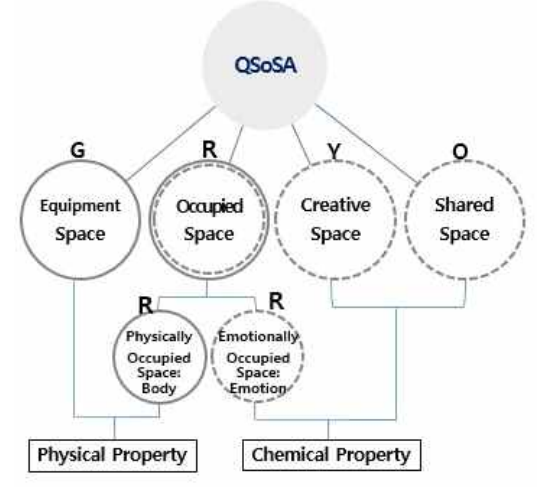

[Fig. 8] Element-Specific Color Characteristic of "QSoSA"

(4) The four elements are integrated and interrelated with each other.

Over the course of stage acting, or over time, the four elements may be separated or 
QSOSA (Quad-Space of Stage Acting) Model for Systematic Space Analysis of Stage Acting Based on Hermann Schmitz's Concept of Space

combined, respectively. The more the four elements of the proposed QSoSA model are combined and integrated, the higher the quality of stage performance. On the other hand, if each element is separated or the combination is weak, it means the quality of the stage performance is low.

(5) Except for "equipment space," the three factors vary in size and position depending on the quality of the stage performance.

The QSoSA model expresses the quality of stage performance through the size of the elements to be expressed. The higher the quality of stage acting, the larger the size of each element is represented. On the contrary, the lower the quality of the stage performance, the smaller it is expressed. This representation may indicate that the magnitude may change over time. In addition, the QSoSA model can express the degree of change in the interrelationship with each element as the position alters. For example, the stage acting quality increases as the size of the intersection signifies that all of the elements are combined.

The "equipment space" with physical characteristics does not change in size and position. However, the "physically occupied space" with physical characteristics of the body can be expressed differently according to the size and extent of the actor's movement and moving lines. The size and location of the interrelationships of the three elements, except for equipment space, are not fixed. Therefore, it can be expressed differently according to the analyst's interpretation criteria and opinions. According to the functional characteristics of (1) - (5), the interrelationship of the four elements presented in the QSoSA model is presented in Figure 9 as an example.

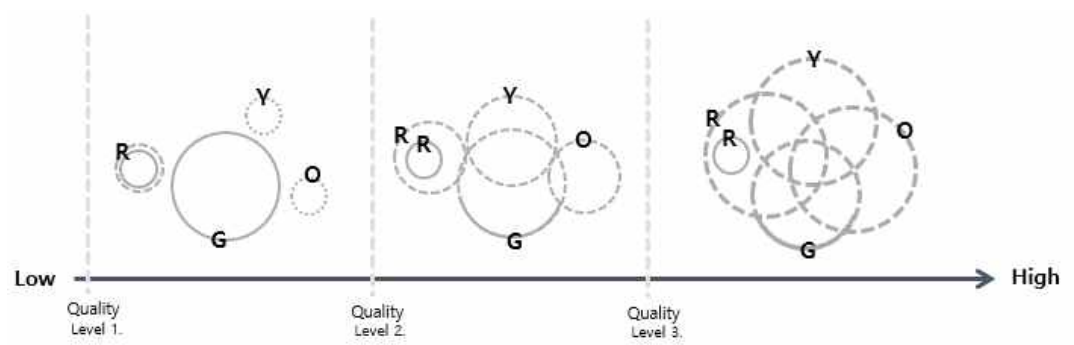

[Fig. 9] Quality-Level Example of "QSoSA": Sizes and Interrelationship

\subsection{Constraints of QSoSA Model}

The proposed QSoSA model has constraints. To use the QSoSA model, the following conditions must be fulfilled, and this model cannot be applied unless it is sufficiently satisfied. 
(1) The unique color of the four elements cannot be represented by any other color.

(2) The unique line shape of the four elements also cannot be represented in any other form.

(3) Of the four spatial elements of the QSoSA model, the physical spaces of the equipment and occupied spaces are essential elements of the QSoSA model, and these two spaces must be included. Of the two detailed elements of the occupied space, the physical occupancy space having physical properties is an essential element; however, the emotional occupancy space having chemical properties is not included in the essential element.

(4) Of the two details of the occupied space, the "Emotionally Occupied Space" cannot be represented independently without the "Physically Occupied Space."

4-1) The "Emotionally Occupied Space" must be accompanied by the "Physically Occupied Space."

4-2) "Emotionally Occupied Space" and "Physically Occupied Space" may be the same or different in size but cannot be separated separately.

(5) In the QSoSA model, when two or more elements are combined, even if the size and position of each element are the same, each element must show its own color and line shape together. For example, if "equipment space," "creative space," and "physically occupied space" are combined in the same size and location, they should be presented in Figure 10.

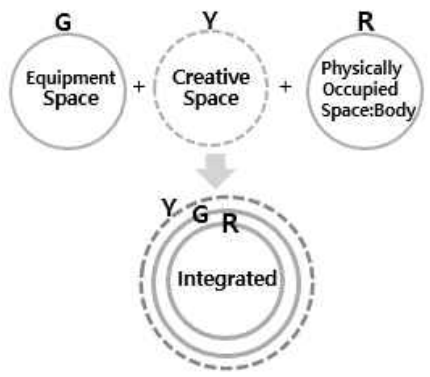

[Fig. 10] Example of When Each Element Is Expressed in the Same Size and Position

\section{Adapting the QSoSA Model to Stage Acting}

The forms and types of modern performances are not all the same in composition, but fictional dramas, such as plays and musicals, are generally composed of the following: "Initiation $\rightarrow$ Development $\rightarrow$ Crisis $\rightarrow$ Climax $\rightarrow$ Ending."

In this chapter, for the application example of QSoSA model, stage acting analysis is explained by applying the process of "Initiation $\rightarrow$ Development $\rightarrow$ Climax" among the stages 
QSOSA (Quad-Space of Stage Acting) Model for Systematic Space Analysis of Stage Acting Based on Hermann Schmitz's Concept of Space

of a general play. However, the physical "equipment space" for the play of the stage can be changed for each scene. However, since it is assumed that the device space is the same, the location of the device space is not mentioned separately in this application case. If the QSoSA model is applied to the flow of stage acting and analyzed, it can be presented in Figure 11.

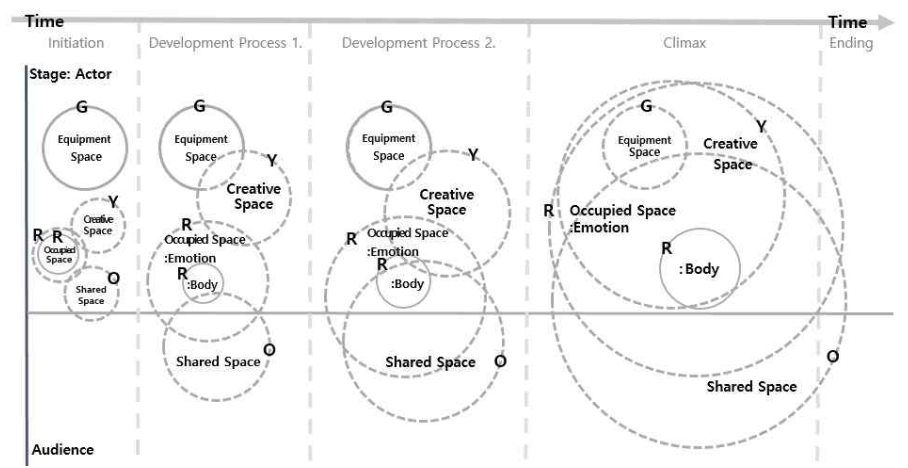

[Fig. 11] Example: QSoSA Applied to the Process of Performance

In the "Initiation" stage-shown in the upper left of Figure 11, where the play begins-the actor's physical and emotional "occupied space" and newly created "creation space," as well as the intersection size combined with the location of the "shared space," are small. Specifically, in the "Initiation" stage, the actor and the audience are immersed in the play, and the degree of identification is not sufficiently achieved.

However, as the play evolves, the stages of "Development Process 1" and "Development Process 2," shown in the upper left of Figure 11, are the actor's "occupied space" and "creation space," and the "shared space" increases. Moreover, the size of the combined intersection between each space increases. In addition, this spatiality affects the space of the audience. In other words, in the "Initiation" stage, the actors and audience are more immersed in the play than in the "Development Process." Furthermore, if the play is successful, the "Development Process 2" phase has a higher degree of space identification than the "Development Process 1." For example, consider that you have a wide range of acting situations (actor's performance, audience's mood, stage environment, season, weather, stage and audience distance, ambient noise, companionship, actor's preference, etc.). If the impression grows, the coupling of these mutual spaces greatly increases.

The upper right corner of Figure 11 represents the "Climax" phase of stage acting. Looking at the circles to be represented in the middle of the right side of Figure 12, it is clear that most form many intersections. This means that when the stage reaches the stage of "Climax," the actor's "occupied space," "creation space," and "shared space" greatly increase, and each 
space is closely related and integrated. In addition, the stage and the audience's spaces are also unified, and the theater's performance space has a significance as a fictional space existing in the stage acting. As a result, it has an "immersive character to acting" that enters into the "space of stage performance" manipulated by the script or the director, which is not a virtual space. In short, the "Climax" phase is a period, in which the essential meaning of the performance is completed. Of course, the stage performance application illustrated in Figure 11 is an example to conceptually demonstrate the QSoSA model. The QSoSA model can be applied not only to the "process of performance" but also based on "specific scene" or the "actor's character." In addition, it has the features and advantages of application to all criteria that can embody the spatiality of stage acting intended by the director. Moreover, the purpose of this analysis is significant because it can be applied in various ways, including communication, factor analysis, or qualitative measurement.

In a future study, we will study how the structure and function of the proposed QSoSA model is combined with the actual stage performance. Additionally, it is important to conduct research on the justification and utilization of the proposed QSoSA model.

\section{Conclusion}

Hermann Schmitz's concept of space-which spatializes emotions-suggests new implications and research perspectives in the study of stage acting, which acts emotions through physical experience in a limited space called "the stage." The QSoSA model has great significance in presenting a reference point for analyzing the theater's structure and stage composition as well as a more detailed analysis of the performance space. Furthermore, as a methodology for discussing and analyzing the meaning of the play's creative space, various spaces are variably fused according to the flow of time through the space characteristics of stage acting with the actor's resulting perspective. There is a greater meaning.

Therefore, the discussion of human emotions is actively discussed not only in the fields of psychology and art but also in various fields, such as engineering and emotional sciences. It is considered that it will have developmental meaning as a basic research on multidimensional fusion performance by combining various computer technologies.

\section{References}

[1] H. R. Kim, The Aspect and Meaning of Visualizing Motion with the Application of Spatial and Expressive 
QSOSA (Quad-Space of Stage Acting) Model for Systematic Space Analysis of Stage Acting Based on Hermann Schmitz's Concept of Space

Elements - Based on Laban's Space Harmony and Phenomenological Interpretation of Movement, Journal of Korean Society of Media and Arts (Contents Plus), (2017), Vol.15, No.5, pp.37-48, DOI: 10.14728/KCP.2017.15.05.037

[2] J. S. Kang, A Study on the Development of K-pop Dance Emotion Model Using Laban's BESS Movement Theory, Journal of Korea Entertainment Industry Association, (2018), Vol.12, No.3, pp.249-266, DOI: 10.21184/jkeia.2018.4.12.3.249

[3] J. S. Ham, J. H. Ryeo and I. J. Ko, Visualizing Emotions with an Artificial Emotion Model Based on Psychology -Focused on Characters in Hamlet-, Korean Society for Emotion and Sensibility, (2008), Vol.11, No.4, pp.541-552.

[4] I. H. Kwon and J. Y. Lim, A Study on the Multi-dimensional Stage space formation process by media Focused on the stage space of $4 \mathrm{D}$ art, Proceedings of the Autumn Annual Conference of Architectural Institute of Korea, pp.271-274, (2004), October 29-30; Jeju, Korea.

[5] H. S. Song, A Study on the Relation between Emotion and Color in Healing Video Art, Society Of Korea Illusart, (2011), Vol.14, No.3, pp.79-86.

[6] S. K. Kim, A Study on the Type and Characteristics of Stage Space in Theater, Journal of the Architectural Institute of Korea (JAIK), (2006), Vol.22, No.11, pp.169-176.

[7] K. S. Kim, Consideration on Differences between a Play and Movie as Media - Focusing on Elia Kazan's movie, <A Streetcar Named Desire>, The Society of Culture \& Arts Content, (2016), Vol.8, No.8, pp.93-135.

[8] B. J. Cho, A Study on the Performance Space Styles of Experimental Theatre Directors in Staging, The Journal of Sciences and Arts, (2008), Vol.11, No.4, pp.145-186.

[9] J. G. Kim, Study on the Performer's Transference and Mental Borderline in a Performance, The Research of Performance Art and Culture, (2012), Vol.25, No.25, pp.57-89.

[10] I. D. Kim, T. Hodson, The Batsford dictionary of drama, Hankukmunhwasa Publishing Co, p.44, (1998), p.44

[11] G. I. Lee, The Science of Inspiration in Acting - the acting training model based on the scientific approach to imagination and image -, Journal of Korean Theatre Studies Association, (2014), Vol.1, No.54, pp.189-240, DOI: $10.18396 / \mathrm{ktsa} .2014 .1 .54 .006$

[12] S. K. Ha, A Phenomenological Redefinitionof the Aesthetic Experience: On the Body-Phenomenology and Aesthetic Theory of Hermann Schmitz, The Journal of Aesthetics and Science of Art, (2006), Vol.23, pp.275-315.

[13] S. K. Ha, Some Reflections on Space, Film and Film-space - Focused on the body-phenomenological theory of Hermann Schmitz, Journal of Contemporary Art Studies, (2008), Vol.12, pp.295-333.

[14] S. K. Ha, A Media-Aesthetic Study ion the Relationship of Modern Media of Images and Spatial Experience, Mihak -The Korean Journal of Aesthetics, (2012), No.71, pp.179-191, UCI: G704-000246.2012..71.006

[15] H. J. Moon, A Model of Recursive Hierarchical Nested Triangle for Convergence from Lower-layer Sibling Practices, Journal of Digital Contents Society, (2018), Vol.19, No.2, pp.415-423, DOI: 10.9728/dcs.2018.19.2.415 